\title{
Vida e morte sujam a urbe moralizada: latidos, mugidos, higienismo e os jornais diamantinenses (virada dos séculos XIX/XX)
}

Life and death make dirty the moralized town: barks, mooings, hygienism and Diamantina's newspapers (turn of the 19TH/20TH centuries)

\author{
Gustavo Leandro "Nassar” Gouvea Lopes *
}

\begin{abstract}
Resumo
Analiso aqui qual intervenção o higienismo, advogado pela imprensa diamantinense da virada dos séculos $\mathrm{XIX/XX,} \mathrm{implicava} \mathrm{a} \mathrm{presença} \mathrm{de} \mathrm{animais} \mathrm{não-humanos} \mathrm{nessa} \mathrm{cidade} \mathrm{mineira.} \mathrm{Um} \mathrm{possível} \mathrm{paradoxo} \mathrm{se}$ revela. Se de um lado, antevendo-se essa vida animal como imunda, o higienismo propunha torná-la alvo de práticas proscritivas até o limite do extermínio, de outro, a negativa higienista frente ao sangue derramado na cidade tendia a condenar essa matança, aparentemente redimindo moralmente essa vida. Qual denominador comum justifica esse impasse que condena ambos princípios da vida animal e da morte na cidade? Ciente de que seres humanos (mediante a prominência da imprensa) constroem suas relações amarrados às teias de significados que eles mesmos teceram, analiso o substrato comum a essas representações, aproximando-me das abordagens da Nova História Cultural. Tal foco, todavia, não deve prescindir de uma análise contextual das relações humananimais ontológicas, voltada à concretude dos animais não-humanos, a partir das suas intermediações materiais com seres humanos - empreendendo-se um trânsito crítico entre tais dimensões analíticas.
\end{abstract}

Palavras-chave: Animais não-humanos; Higienismo; História urbana; Moral.

\begin{abstract}
I am analyzing here what intervention the hygienism, lawyered by the Diamantina's press at the turn of the 19th/20th centuries, implied the presence of non-human animals in this Minas Gerais town. A potential paradox is revealed. If by one side, in anticipation of this animal life as filthy, the hygienism implied in making it target banning practices, to the extent until the extermination, in the other side the negative position of the hygienism before bloodshed in the city tended to condemn the killing, apparently by redeeming this life morally. What denominator commom justifies this impasse that condemns both principles of animal life and death in the city? Aware that human beings (through the prominence of the press) build their relationships tied to webs of meaning that they themselves spun, I analyze the common substrate to these representations, coming close to approaches of the New Cultural History. Such focus however should not dispense a contextual analysis of the ontological humananimals relations, for nonhuman animal's reality, from its brokerage materials with human beings - undertaking a critical transit between such analytical dimensions.
\end{abstract}

Keywords: Non-human animals; Hygienism; Urban history; Moral.

\footnotetext{
* Mestre pelo Mestrado Profissional Interdisciplinar em Ciências Humanas pela Universidade Federal dos Vales do Jequitinhonha e Mucuri (UFVJM). Funcionário do Ministério da Fazenda - Receita Federal de Diamantina-MG.
} 


\title{
Introdução
}

Com o volume da atuação política vegana ${ }^{1}$, desde o fim do século XX, - como prática capaz de evidenciar a libertação dos animais não-humanos ${ }^{2}$ enquanto necessidade global -, novas questões históricas vão se tornando salientes. Este artigo foi fomentado a partir de minha pesquisa de mestrado, que buscou entender o processo de proscrição dos animais não-humanos de Diamantina - cidade mineira localizada no Vale do Jequitinhonha. O recorte cronológico coteja estrategicamente o alvorecer de sua modernização, época em que a presença animal não-humana na cidade era ainda muito intensa.

A respeito dessa presença massiva de animais não-humanos em Diamantina no momento da virada de séculos em questão, Goodwin Jr. (2007) anota:

\begin{abstract}
Muares que pastam, vacas a mugir, sapos coaxando em coro enlouquecedor. Os animais representariam junto com os mosquitos, a chuva, os rios transbordantes, o mundo bárbaro, rural, selvagem - tão vigorosamente associado à natureza pelo imaginário romântico ocidental! A civilização aparece, como em outros momentos, como frágil biombo amparando a urbe. Em Diamantina, a questão havia se tornado tão problemática, que a edilidade tomou medidas drásticas, passando a confiscar animais desgarrados. (GOODWIN Jr., 2007, p. 201).
\end{abstract}

Para fins dessa pesquisa, entendeu-se Diamantina como lócus que (re)produz uma tendência global na qual animais não-humanos passam a ser vistos como um problema para as urbes modernizadas e higienizadas. Qual seria a relação desse

\footnotetext{
${ }^{1}$ Veganismo é a tradução do abolicionismo animal para o cotidiano, restringindo-se às obrigações de "não cometer" indivíduos humanos perante indivíduos não-humanos. Ele vincula táticas de boicote a alimentos/produtos formados com tecidos extraídos de corpos sencientes não-humanos, buscando afetar sua produção e, mais ainda, sua legitimidade fundante. Também vincula o boicote a empresas que aprisionam, machucam e matam tais animais sencientes a título de experiências científicas/produtivas. Assinala ainda uma recusa à participação em outras atividades tais como cavalhadas, touradas, rodeios, zoológicos, charretes, etc. Pode fossilizar-se em um conjunto de hábitos, dando impressão de uma lista arbitrária de mandamentos a seguir, quando alienado da motivação ética que o fundamenta. Recentes debates têm analisado essa possível defasagem entre ações de praticantes do veganismo e a motivação ética que o fundamenta - em busca de tornar a libertação da animalidade não-humana sob jugo humano mais contundente. Mais recentes, ainda, são as discussões a respeito das ações éticas a serem empreendidas em benefício dos animais não-humanos sencientes que vivem em paisagens selvagens em benefício, portanto, de indivíduos de outras espécies que são geralmente desconsiderados, por padecerem sob forças entendidas como naturais. Tais teses que apontam ações positivas frente a animais selvagens são chamadas "intervencionistas", e são (ainda?) conhecidas por uma pequena vanguarda de ativistas veganos.

${ }^{2}$ O termo "animal não-humano" é utilizado necessariamente em continuidade a outro termo, elíptico: "animal humano". A razão dessa escolha é ressaltar a fronteira aberta entre ambos, evidenciada por um denominador comum ("animal"). A fonte legitimadora desse uso advém tanto da etologia contemporânea (LESTEL, 2002; BEKOFF, 2010) quanto do veganismo abolicionista (FRANCIONE, 2013). Por meio do reequacionamento dos termos, busca-se evidenciar a existência de características compartilhadas entre tais entes - em especial a senciência.
} 
processo de rejeição com a defesa, cada vez mais saliente, de que animais não-humanos devem ser libertados do assujeitamento imposto pela(s) sociedade(s) humana(s)? Essa foi a pergunta fundadora de minha pesquisa.

Foi escolhida a imprensa diamantinense como fonte primária, tendo em vista seu papel na proscrição dos animais não-humanos da urbe, a título de higienizá-la (GOODWIN Jr., 2007). Tal papel, não se resumindo a denúncias e reclamações direcionadas à edilidade contra essa presença animal na urbe, adquire contornos mais implícitos, através da representação dos animais não-humanos como arquétipo oposto à civilidade almejada.

Uma das consequências da opção por esse conjunto de fontes foi o cotejamento de vários tipos de textos citando a animalidade. Em sua heterogeneidade, incluem-se tabelas de preços, anúncios, contos literários, poemas, receitas gastronômicas, textos científicos, notícias, leis municipais, textos sobre disputas eleitorais, escritos historiográficos etc.

Uma pesquisa em maior profundidade demandaria a leitura de toda uma bibliografia transversal que dinamize cuidados metodológicos para cada um desses tipos de fonte em questão. No entanto, as limitações temporais do mestrado assim não permitiram, priorizando-se transversalmente textos etológicos, filosóficos e/ou ligados à ética animalista.

\section{Contemplando associações: a animalidade nas constelações simbólicas do mal}

Recorrentemente, o higienismo - que já se insinuava desde o século XVIII - é evocado como uma das arestas fundamentais, a partir da qual a recusa de proximidade com animais não-humanos foi levada a cabo. O higienismo faz-se presente nesse processo de proscrição a partir de uma percepção de que a animalidade é suja e/ou que ela atua sujando a cidade, anteriormente mesmo ao entendimento científico desses animais como portadores de micro-organismos que adoeciam a população humana.

Para Sennet (2003), a emergência de um urbanismo imperioso em tornar a cidade um espaço de medicalização, de purificação e de remoção da sujeira está intimamente relacionada ao paradigma modernizador do espaço. Esse paradigma, via capitalismo, prevê a cidade enquanto lócus de aceleração e automação produtiva, que passa a investir os ritmos ontológicos do corpo animal como sintomas de atraso. Importa, nessa constelação, destacar o quanto esse higienismo apresenta-se também 
como uma criptografia científica e técnica da moralidade, em sua busca pela assepsia (inclusive moral) da paisagem urbana. Nesse imaginário, o imoral e o anti-higiênico se imbricam redundantemente um ao outro, num continuum. Segundo Sennett (2003, p. 214): “A revolução médica parecia ter operado a troca de moralidade por saúde [isomórficas entre si] — e os engenheiros sociais estabeleceram a identidade entre saúde e locomoção/circulação." Esse paradigma higienista emerge como uma criação urbana, demarcando um contraste com a ruralidade. Sennet (2003), a seguir, assinala que higienização, modernização urbana, moralidade e rejeição das substâncias corporais não são alheias entre si. Este último item, sintomaticamente, evidencia um denominador comum a toda animalidade. Sendo assim, não parece fortuito que o paradigma higienista coincida com a idealização da cidade como lugar onde o corpo animal deva ser proscrito, em benefício de tecnocracias assépticas. Ideia que se complementa pela estipulação do campo (e/ou da natureza ${ }^{3}$ ) como o lugar certo para os animais nãohumanos.

A respeito dessa higiene como tipicamente urbana, Sennett (2003) diz que:

\begin{abstract}
Entre os camponeses, a sujidade incrustada na pele parecia natural, capaz até mesmo de proporcionar saúde. Urina e fezes humanas ajudavam a nutrir a terra; deixadas no corpo, bem que poderiam formar uma película revigorante, especialmente para crianças. Daí ser tão comum às pessoas do campo acreditarem que "ninguém deve lavar-se com muita frequência [...] porque a crosta de fezes secas e restos de mijo faziam parte do corpo e protegiam, especialmente crianças recém-nascidas [...]". Limpar escrupulosamente as fezes do corpo tornou-se uma prática particularmente urbana e de classe média. [...] Afinal, tratava-se de uma noção formulada na cidade e divulgada por aqueles que a revelaram, eles próprios cidadãos urbanos. (SENNETT, 2003, p. 219).
\end{abstract}

Fechando-se a contemplação dessa constelação simbólica em torno do higienismo, surgem intercambiáveis entre si a rejeição intransitiva das evidências corporais (portanto não me refiro somente a pouco problematizável recusa dos excrementos) e a necessidade de banir a animalidade não-humana para o campo e/ou para a natureza, antíteses da cidade. Tal gesto criptografa uma fronteira mutuamente excludente entre limpeza e sujidade, entre espírito humano e corpo animal. Assim, no paradigma civilizatório ortodoxo, que dá luz à equação higienista, o animal nãohumano, sendo pura evidência corporal sem espírito, é anti-higiênico: é imoral.

\footnotetext{
${ }^{3}$ Essa ideia é também encampada pela ecologia normativa - em especial pela ecologia profunda -m ainda que com sinais valorativos invertidos. Observa-se uma redundância entre essa ecologia e o modelo civilizatório ortodoxo no que tange aos imperativos da animalidade. Sobre os fundamentos dessa circularidade ver: A imprensa e a proscrição dos animais não-humanos da urbe diamantinense (1894-1912).
} 


\section{Animais não-humanos: sujeira moralmente incurável}

A percepção da cidade moderna como lugar da urgência sanitária, e assim da animalidade como alvo dessa intervenção higienista, é correntemente expressa pelos jornais diamantinenses, em diversas passagens.

No ponto de tensão existente entre a força do hábito e a eloquência da higienização propagada pelos anseios modernizadores - frente aos quais personalidades da imprensa interpuseram-se como guias especiais - estão situados os textos dos jornais. São pontos nodais por onde circulam sub-repticiamente os afluentes do dia a dia. Mas mais ainda: na qualidade de agentes interessados na transposição conscienciosa dessas águas, tais jornais desempenharam um papel ativo nesse processo de higienização da cidade (GOODWIN Jr., 2007).

Os jornais diamantinenses representam notícias nas quais fica patente a presença de animais não-humanos no cotidiano da cidade. De tais textos se depura a participação dessa imprensa fomentando a proscrição desses animais, às vezes sob forma de denúncias ou reclamações vinculadas contra essa presença, mas também por itinerários mais sutis. Ou, no outro extremo, por meio de elogios à pura matança.

O jornal A Idéa Nova participa-nos de uma prática: o morticínio dos cães que viviam nas ruas. Tanto era comum tal prática, que a Câmara Municipal ganhara o apelido de "Club Mata Cães". Tais medidas foram apoiadas pela redação, legitimandoas pelos exemplos irradiados das cidades mais modernas do país:

\footnotetext{
O nome do Club encerra em si seu fim unico e elevadamente patriótico. No Rio de Janeiro e S. Paulo leva-se a effeito, com grande dificuldade, o extermínio dos ratos, propagadores da peste bubonica. Entre nós, porem, o Club arca com muito maiores empecilhos para a extinção radical de cães, e nem por isto deixa de trabalhar com [ilegível] que indubitavelmente exige grande soma de energia e coragem. (BIBLIOTECA ANTÔNIO TORRES. IPHAN-DIAMANTINA, 1906, p. 1). ${ }^{4}$
}

O processo de proscrição dos animais não-humanos, índice/causa de assepsia no ambiente urbano, atua sobre outras espécies sencientes que não cães, e não necessariamente exige extermínio. É o caso dos animais submetidos ao tropeirismo, cuja presença incomodava, mas por conta de sua participação estruturante no circuito socioeconômico diamantinense, enquanto propriedade produtiva, não se apregoava a sua matança. Verifica-se uma queixa nesse sentido:

\footnotetext{
${ }^{4}$ BiblioteCA ANTÔNiO TORRES. IPHAN-DiAmAntinA, MG. Club mata cães. A Idéa Nova, Diamantina. 29 jul. 1906. p. 1.
} 
Causa estranheza e desolação mesmo ao observador menos exigente, o lamentavel estado da praça Barão de Guaicuhy, uma das mais habitadas e centraes da cidade. Alli se acham o mercado dos generos alimenticios e mais repugnante estrumeira, paraiso das moscas, devido a permanencia dos animaes naquelle ponto durante longas horas do dia. A camara poderia attender ao assumpto, proibindo essa permanência, inconveniente sob todos os pontos-de-vistas. (BIBLIOTECA ANTÔNIO TORRES. IPHANDIAMANTINA, 1906, p. 6). ${ }^{5}$

Se era impossível solicitar a erradicação dessa presença, importava discipliná-la a lugares mais recônditos e apropriados, previamente designados para esses animais, de modo a minimizar a coabitação de diamantinenses com tais.

A emulação dessa proscrição como item de medicalização da urbe adquire maneiras mais sutis. Esse é o caso do jornal O Jequitinhonha no ano de 1904 que, aparentemente, nada registrou de queixa a respeito dos incômodos que a considerável presença de animais não-humanos imputaria aos indivíduos humanos de Diamantina. Exemplares desse ano noticiam, entretanto, um processo de proscrição de animais nãohumanos no Rio de Janeiro. Essas menções trazem referências implícitas ao processo vivenciado por Diamantina, reforçando-o. Essa é a característica performativa do discurso jornalístico ao gerir, junto a seu público leitor, uma grade de valores que, por sua vez, sacramenta determinados horizontes de expectativas nesse público.

Esse jornal nos evidencia o processo de urbanização carioca como um belo exemplo a ser seguido. O desaparecimento de animais vetores de doenças na cidade surge como motivação e, ao mesmo tempo, sintoma do sucesso desse processo:

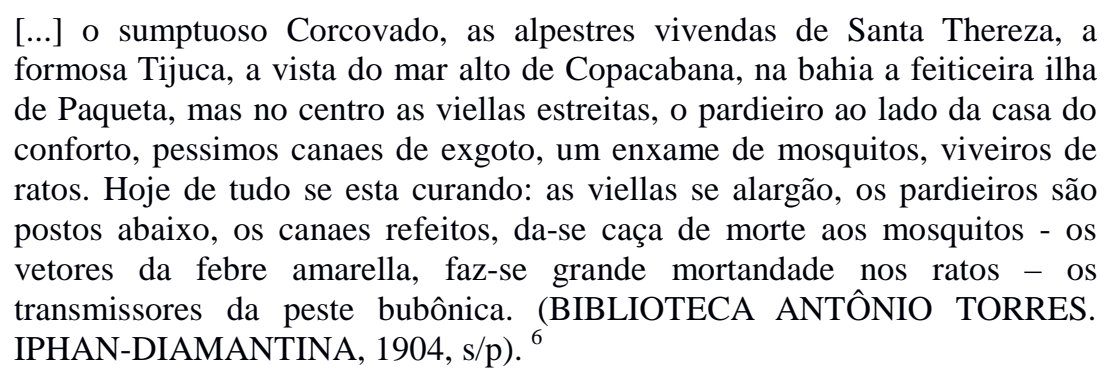

Importante notar como a necessidade de livrar a elite carioca desses animais se conjuga para aquém e para além das meras técnicas de saneamento. E isso nos leva a crer que as razões para a proscrição de animais não-humanos detém raízes mais

\footnotetext{
5 BIBLIOTECA ANTÔNIO TORRES. IPHAN-DIAMANTINA, MG. Queixas. A Idéa Nova, Diamantina, 6 maio 1906. p. 3.

${ }^{6}$ BIBLIOTECA ANTÔNIO TORRES. IPHAN-DIAMANTINA, MG. Carta do Rio. O Jequitinhonha, Diamantina. 22 maio 1904. s/p.
} 
profundas do que a irresistível e comprovadamente científica necessidade de sanear os espaços dos perigos da doença (em seres humanos). De fato, perpassa no discurso em questão uma profunda oposição simbólica, por vias de uma oposição estética. O campo da feiura, como se vê, é representado pela presença animal. A pretexto da justificativa imediata de proteger a espécie humana dos sofrimentos da doença, o texto nos remete a uma razão simbólica nesse processo, que compreende a animalidade tautologicamente negativa aos olhares humanos. Para aquém e para além dos argumentos de saneamento das doenças, pela depreciação estética, a animalidade é insinuada como alvo intransitivo desse higienismo.

Em 1912, A Idéa Nova nos adverte da imundície em um beco da cidade diamantinense. Em uma paisagem dantesca a figura canina está sublinhada como um dos sintomas autoexplicativos dessa sujeira, alvo que o higienismo deve sanar. Não há nessa caracterização negativa nenhuma (necessidade de) justificativa dos cães serem portadores de agentes patogênicos. Não obstante, a sujeira (moral) da cidade está intrinsecamente vinculada à presença dos cães. Afirma-se:

\begin{abstract}
Resto dos tempos do Tijuco existe aqui em Diamantina um becco estreitissimo, sinuoso, immundo, onde vivem em promiscuidade muitos infelizes, lembrando o celebre CABEÇA DE PORCO do Rio. Ha dias passados, num dos quartos d'esse becco onde mora Maria Pipoca, que tem a mania da creação de cães, uma mulher por alcunha Maria Pesinho abortou uma creança quasi viavel, que morreu pouco depois, e por descuido e desleixo da gente da casa, foi devorada pelos cães. (BIBLIOTECA ANTÔNIO TORRES. IPHAN-DIAMANTINA, 1912, p. 3). ${ }^{7}$
\end{abstract}

A proscrição da vida animal não-humana - sobre o imaginário basilar da animalidade como tautologicamente suja - torna indistintos os argumentos de saneamento de agentes patogênicos quanto os argumentos de retidão moral, a ponto de não ser mais necessário justificá-los. Tudo se passa como se nesse viés antianimal ambos os sentidos estivessem automaticamente inscritos, autoevidentes, como se essa rejeição simbólica portasse não problematicamente ambas as faces cindidas do discurso higienista.

Há sempre algo a mais e a menos nesse discurso higienista que veicula negativamente a animalidade, visto que inúmeras vezes prescinde das justificativas de saneamento, de combate às doenças (humanas). Tudo se passa como se animalidade fosse em si mesma a sujeira. O Jequitinhonha, por exemplo, imprimia valorações

\footnotetext{
${ }^{7}$ BIBLIOTECA ANTÔNIO TORRES. IPHAN-DiAMANTINA, MG. Devorado por cães. A Idéa Nova, Diamantina. 21 jan. 1912. p. 3.
} 
negativas à presença de animais não-humanos, representando-os como causa/sintoma de uma degradação sociocultural. Num relato no qual o redator consuma sua visão assustada com a miséria humana reinante em Peçanha, diz-se:

Por esta simples narrativa, calcula-se que, no meio das frondosas mattas do Peçanha existem muitas familias sem recursos de qualidade alguma, devido ao seu pouco amor ao trabalho. E é sabido que uma pessoa mal alimentada em uma morada rodeada de expessa floresta, edificada junto a pantanos, revolvidos pelos suinos, desprendendo um fetido insuportavel, não pode ter sadure (BIBLIOTECA ANTÔNIO TORRES. IPHAN-DIAMANTINA, 1904, $\mathrm{s} / \mathrm{p}){ }^{8}$

A proximidade com porcos é vinculada à preguiça, à pobreza, ao atraso, à falta de desenvolvimento econômico, esboçando-se a culpabilização do pobre pela pobreza gestando-se uma aberrante zona de indeterminação entre seres humanos e outras espécies animais. As habitações são retratadas negativamente de modo a nos remeter aos covis onde moram nuas feras: "As paredes são de páos em pé, de maneira que de fora encherga se todo o interior da casa, salvo alguns logares que vedão por meios de esteiras. A vegetação cresce até junto as paredes sem que os moradores se encommodem com isto!" (BIBLIOTECA ANTÔNIO TORRES. IPHAN-DIAMANTINA, 1904, s/p). ${ }^{9}$ Mais à frente o autor retrata uma senhora "acariciando os filhinhos, tão sujos que ela mesma os chamava de gatinhos rajados" (BIBLIOTECA ANTÔNIO TORRES. IPHANDIAMANTINA, 1904, s/p). ${ }^{10}$

\section{Um parêntesis: a sacrificalidade animal estruturante das relações humanas}

Quando não basta simplesmente nascer homo sapiens para ser investido da imunidade asséptica que a humanidade comporta; quando o humano se exercita para dar provas de sua humanidade, de sua não-animalidade, e assim sacramentar sua imunidade frente ao investimento contra sua vida, aquela pessoa que desonra esse pertencimento fica à mercê, no limite, de ter o mesmo destino reservado aos animais não-humanos. A nudez ocasionada pelo despir das honras que humanizam lança esse ser humano mais próximo da zona (de matabilidade) animal.

8 BIBLIOTECA ANTÔNIO TORRES. IPHAN-DIAMANTINA, MG. Lagoa de Peçanha. O Jequitinhonha, Diamantina. 14 jul. 1904. s/p.

9 BIBLIOTECA ANTÔNIO TORRES. IPHAN-DIAMANTINA, MG. Lagoa de Peçanha. O Jequitinhonha, Diamantina. 14 jul. 1904. s/p.

10 BIBLIOTECA ANTÔNIO TORRES. IPHAN-DIAMANTINA, MG. Lagoa de Peçanha. O Jequitinhonha, Diamantina. 14 jul. 1904. s/p. 
Segundo Cary Wolfe (2013), a desumanização que antecede a matabilidade, tornando sacrificial a própria vida humana, é um mecanismo pautado numa longa duração da temporalidade ocidental. Tal mecanismo "zoomorfizante" parece especialmente cotejado nessa saturação modernizante típica de meu recorte cronológico - período de forte consenso em torno daquele progresso civilizatório, de afastamento intransitivo da animalidade. É Wolfe quem afirma:

Butler está certamente correta, como muitos filósofos têm enfatizado, quanto à "desumanização" como um mecanismo fundamental para a produção de uma ideia ocidental do "homem" sobre e contra as populações consideradas "duvidosamente humanas". Mas, como argumentei em detalhe em outro lugar, enquanto o padrão da exclusão automática de animais [do campo de consideração ética] permanece intacto, simplesmente por causa de suas espécies [especismo], tal desumanização por meio do mecanismo discursivo de "animalização" estará prontamente disponível para implantação contra qualquer indivíduo que cair fora do "nós" etnocêntrico. ${ }^{11}$ (WOLFE, 2013, p. 13 - tradução do autor).

É notável que o higienismo que analiso neste artigo articule uma moral humana. E ele, obviamente, volta-se contra grupos humanos, quando eles são ou agem "como animais", desonrando sua humanidade. Aqui talvez valha a pena repensar em que medida o higienismo se efetivou justamente na razão de recalcar tudo que remetesse a espécie humana à (sua) animalidade.

Norbert Elias é um autor que nos encoraja a desconstruir o discurso tecnocrático do higienismo, procurando nele razões profundas que estão vinculadas mais ao domínio dos valores, na ordem do mundo simbólico, do que na mera prevenção dos sofrimentos (humanos) da doença. Ele anota:

\begin{abstract}
Isto não corresponde à expectativa que talvez tenha um observador do século XX. Ele, por exemplo, acha, talvez, que a eliminação do hábito de "comer com as mãos", a adoção do garfo, as louças e talheres individuais, e todos os demais rituais de seu próprio padrão podem ser explicados por "razões higiênicas". Isto porque é esta a maneira como ele mesmo explica, de modo geral, esses costumes. Mas o fato é que, em data tão recente como a segunda metade do século XVIII, praticamente nada desse tipo condicionava o maior controle que as pessoas impunham a si mesmas. De qualquer modo, as chamadas "explicações racionais" têm bem pouca importância em comparação com outras. (ELIAS, 1993, p. 122).
\end{abstract}

\footnotetext{
11 Butler is certainly right, as many philosophers have emphasized, that "dehumanization" is a fundamental mechanism for producing a "Western" idea of the "man" over and against populations considered "dubiously human." But as I have argued in detail elsewhere, as long as the automatic exclusion of animals from standing remains intact simply because of their species, such a dehumanization by means of the discursive mechanism of "animalization" will be readily available for deployment against whatever body that happens to fall outside the ethnocentric "we".
} 
Depura-se um cuidado para que não aceitemos acriticamente o discurso higienista. Tal discurso pode ofuscar a existência de outras razões que estão espraiadas às margens do seu discurso oficial, assentando-o: o que vale para a explicação dos garfos às mesas deve valer também de maneira homóloga à proscrição dos animais nãohumanos, quando se alega a falta de higiene pertinente a eles. Nesse processo civilizatório que conforma o higienismo como um ponto específico e particularmente visível desse itinerário, Elias anota, para fins deste artigo, sua tese: "Será demonstrado que as pessoas, no curso do processo civilizatório, procuram remover em si mesmas todas as características que julgam animais." (ELIAS, 1993, p. 128).

Já é grande a gama de estudos que tem se atentado para uma análise que seja capaz de desvendar saberes e motivações menos aparentes que conformam o discurso higienista. $\mathrm{O}$ estabelecimento de uma nova modalidade de controle sobre/contra os corpos através do discurso higienista foi percebido por Magnani:

\begin{abstract}
As transformações pelas quais passava o Brasil no final do século XIX, como já aqui mencionado, exigiram novos mecanismos disciplinares, no bojo dos quais se implantou uma medicina social no Brasil. A desorganização da sociedade como um todo, diante das novas atividades econômicas e suas consequências, foram consideradas um risco para a saúde pública. No sentido de atuar junto aos possíveis focos de enfermidade em todas as instâncias sociais, o discurso médico propôs uma medicina social que regulasse permanentemente os espaços urbanos, as instituições e até mesmo o comportamento dos indivíduos. (MAGNANI, 2004, p. 77).
\end{abstract}

Qual categoria fornecia o protótipo a partir do qual o higienismo exercia como ondas seus poderes sobre a sociedade, normatizando-a? Magnani (2004) parece nos responder:

\begin{abstract}
Com estes dados, pode-se vislumbrar quem eram considerados normais em Diamantina no final do século XIX e princípio do século XX: os homens brancos, de posses, pais de família, seres racionais e as mulheres casadas, mães de família das classes médias e altas, dóceis, submissas, boas esposas e sem desejos. O que nos dá (ainda que não tenhamos dados quantificáveis tão claros como em outras instituições do Brasil) o perfil social dos nossos loucos: negros e mestiços, pobres, escravos ou trabalhadores simples, mendigos ou desocupados e mulheres, que, mesmo protegidas pelo casamento e pelo marido, poderiam, a qualquer momento perder a razão em função de sua fragilidade natural. Ontem, como hoje, negros, pobres e mulheres pertencem às categorias perigosas da sociedade. (MAGNANI, 2004, p. 85).
\end{abstract}

Ocorre que a mesma autora fornece subsídios para que - dentro de um continuиm que vai da normalidade à anormalidade - pensemos num elemento implícito, um elemento arquetípico subjacente. Seres humanos tidos como loucos tendem mais ou 
menos a se aproximar e a se alinhar a este elemento, ficando à mercê dos destinos regularmente reservados a este arquétipo: o animal não-humano. Para Magnani (2004, p. 88) “o Hospício de Diamantina foi, de um lado, uma resposta à necessidade de isolamento dos loucos que, soltos pelas ruas interferiam no redimensionamento da cidade e na sua necessidade de desenvolvimento ordenado". E o raciocínio se completa: "Seu tratamento adequado no hospício, significa há um tempo, a busca da normatização como objetivo e perspectiva de cura, e a limpeza exigida pelos novos espaços urbanos." (MAGNANI, 2004, p. 83 - grifo meu).

Destaca-se a semelhança entre as motivações/estratégias devotadas aos seres humanos tidos como sem razão e aos animais não-humanos: o corpo improdutivo-sujo, em ambos os casos, é visto como alvo da higienização na urbe. Geminados em sua irracionalidade constituinte, são presos e isolados em locais análogos, fora das ruas. Num mesmo sentido e direção, mas com intensidades distintas: à gente entendida louca era cedido um espaço de cura, de retorno ao humano, uma antessala conceitual que a resguarda do plano imediato da matabilidade animal. Já ao arquétipo antitético da normatividade humana - "o animal" - não havia possibilidade de reabilitação ou cura. No máximo: a comodificação pela pecuária e/ou pelo tropeirismo, mas em especial nas sendas de uma zootecnia que emergia a essa época, podia adiar a matabilidade desses animais. Fazendas ou pastos longes do centro urbano são os lugares apropriados a esses animais (quando geradores de renda, já que incuráveis), assim como o hospício é para loucos (mas aqui pela possibilidade de cura de sua animalidade). Quando não rentáveis, os animais não-humanos, sem cura de sua sujeira, deviam ser imediatamente mortos, caso dos cães: à antítese arquetípica da normalidade higiênica humana se preparavam consequências bem sectárias.

A mesma lógica "zoomorfizante" que valeu para loucos parecia valer para outras individualidades humanas que se localizavam à margem dessa imunidade: quanto mais se aproximavam da zona de animalidade, mais anormais, menos direitos tinham. Quanto mais se aproximavam dessa animalidade, mais se tornavam matáveis ou, no mínimo, aprisionáveis: a prisão é a antessala, onde se gesta a possibilidade de cura (pelo casamento monogâmico, pela religiosidade, pelo trabalho, etc.).

Também em nome da higiene (moral) pública, seres humanos empobrecidos acusados de vadiagem tornar-se-iam alvos de detenções em Diamantina no período estudado: 
Mais do que isso, [o trabalho] é elemento formador do caráter, gerando através da sua prática regular várias virtudes [humanas], além do consequente progresso material. Este caráter educativo, formador da pessoa, é que transcende a necessidade econômica como razão para o trabalho: mesmo aqueles que não precisariam trabalhar para viver devem fazê-lo, porque todos "têm alguma cousa que fazer" [...] Estamos a um passo da criminalização do ócio, que no caso dos pobres era designado por outro nome: vagabundagem. (GOODWIN Jr., 2007, p. 233).

Goodwin Jr. (2007) é eloquente em exemplos de desconfianças emuladas pelos jornais diamantinenses. Sem o trabalho e/ou o capital - que civilizam, afastando o ser humano da zona de animalidade - a vadiagem (a mendicância, a embriaguez e o nomadismo) se torna alvo de culpabilização punitiva e de aprisionamento. São antessalas da matabilidade legitimadas pela possibilidade de cura. Esse autor transcreve de um jornal diamantinense de fins do século XIX um trecho elucidativo desse discurso associativo da "zoomorfização", que gesta no limite essa sacrificialidade:

De dia pede esmola; à noite exigia. À hora da missa encontra-se à porta de egreja; e é o mendigo; à hora do crime encontra-se à esquina de viellas, e é o ladrão. De dia traz muletas, de noite traz navalas [...] D'onde veio esse homem? Da prostituição, do lodo anonymo. Entrou na vida pelo postigo de uma roda e ha de sahir pelo alçapão da guilhotina. Rompeu de um ventre como um sapo de um esgoto (Sete de Setembro, 26 fev. 1887 apud GOODWIN Jr., 2007, p. 265 - grifo meu).

O higienismo implicava a restrição da liberdade das mulheres, nessa rua limpa que os jornais pretendiam erigir, que se encontravam alçadas a uma condição mais próxima da animalidade (associada aos impulsos, aos instintos, à libido e à lascívia). Dayse Santosanalisando as vinculações entre higienismo, moralidade e as mulheres em jornais diamantinenses nos diz que:

Na realidade, é como se houvesse um tripé que não poderia ruir: a sociedade tinha na família o sustentáculo de sua existência, e esta, por sua vez, identificava na instituição do casamento uma base teoricamente firme. Já o casamento estava atrelado à figura feminina ideal como eixo principal da vida conjugal. O tripé - família, casamento e figura feminina ideal - jamais poderia ficar manco, o que justificou a preocupação com as mulheres e a necessidade de circunscrever seu principal espaço de atuação, qual seja, o lar doméstico. Em seus estudos, Margareth Rago afirmou que o discurso burguês buscou representar a esposa-mãe-dona-de-casa como ordeira e higiênica. Contrapondo-se a essa imagem, a mulher prostituta figurava como pecadora e diabólica. Essas duas imagens polarizadas de mulher possuíam um ponto em comum: as mulheres "eram submissas, dependentes, porcelanas do homem, incapazes de um pensamento racional e consequentemente de dirigirem sua própria vida". (SANTOS, 2003, p. 15 - grifo meu).

Havia uma interdição também para a africanidade. A associação dela ao primitivo aproximava pessoas negras da animalidade, colocando-as sob suspeita. Uma 
política higienista parecia derivar num branqueamento da urbe - tornando os corpos negros mais controlados, mais aprisionáveis e, num ápice gradativo, mais matáveis. Diz Goodwin Jr. (2007):

\begin{abstract}
A apropriação de algumas características do modelo de transformação do espaço urbano era uma forma aparentemente viável de um país mais pobre aproximar-se do padrão de vida europeu/estadunidense, instalando parte da infra-estrutura da modernidade. Isto era facilitado por características intrínsecas ao próprio processo de reformulação do espaço urbano, como sua concretude e visibilidade, bem como seu caráter explícito de representação. No caso específico do Brasil, essa política trazia uma série de vantagens correlatas: a possibilidade de ampliar o controle social sobre as emergentes classes populares, especialmente os negros e mulatos; a oportunidade de cunhar um novo projeto de identidade social para os núcleos urbanos, numa política de branqueamento cultural e de europeização dos espaços. (GOODWIN Jr., 2007, p. 36).
\end{abstract}

A imputação, pelo higienismo modernizador no país, de seres humanos de pele negra como uma presença problemática - que, no limite, deveria ser substituída por outra presença - foi notada por Nísia Trindade Lima (1999):

\begin{abstract}
A literatura sobre o tema indica que dificilmente se poderia falar de pensamento social brasileiro e da presença do discurso higienista, sem referência à noção de raça na elaboração de interpretações sobre o Brasil. Ideias de inferioridade racial compõem um quadro explicativo sobre o país. Especialmente na segunda metade do século XIX, vê-se a expressiva influência, entre as elites políticas e intelectuais, das teorias europeias sobre inferioridade racial. Para alguns intelectuais, os obstáculos representados pela base racial eram insuperáveis. Sob a influência de teóricos como Gobineau, Agassiz e Le Bon, apontavam um programa intenso de imigração como única saída favorável. Dentre as diversas correntes, destacavam-se os que afirmavam uma saída "mais otimista", encontrando-a num processo progressivo de "branqueamento" do Brasil. Em quaisquer dessas versões, é possível identificar como diagnóstico comum aquele que via o principal problema da nacionalidade no povo [negro] que, no limite, deveria ser substituído. (LIMA, 1999, p. 114).
\end{abstract}

No limite mais ou menos abertamente declarado, especula-se a destituição culpabilizadora de um grupo catalisado pela/desde a mesma necessidade de estigmatizar e dominar. E o que concretamente importa, pois é vivenciado pelo corpo, mais aquém, no limite sub-reptício que está caindo fora da linguagem oficial, em especial da linguagem jurídica, é a possibilidade da destituição (extinção) dos indivíduos reais, de pele negra, que foram agregados por esse enquadramento (racista) em grupos raciais.

Segundo Cary Wolfe (2013), Foucault teria percebido que a temática da raça criptografa uma especiação dentro da própria espécie humana. Falar de raça seria, no limite, falar de espécie, falar da animalidade que enfrenta as fronteiras do humano, e de sua sacrificialidade: 
Retornamos, então, não só ao lócus tanatopolítico dos campos, tomado como ponto central do trabalho de Agamben, e não só à questão do estatuto biopolítico do Nazismo, mas também à função central de raça - e, por extensão, de espécies - na biopolítica moderna. Como é bem sabido, Foucault explora este tópico nos estudos de 1975-1976 agrupados em "Em Defesa da Sociedade". O racismo, tal como Foucault nota, cria "cesuras dentro do continuum biológico endereçado pelo biopoder"; é "um modo de fragmentar o campo da biologia que o poder controla" de modo que algumas populações possam ser mortas ou deixadas a morrer - o que Foucault chama sem rodeios de "assassinato indireto". "Numa sociedade normativa," ele escreve, "a morte da raça ruim, da raça inferior (ou do degenerado, do anormal) é algo que tornará a vida em geral mais saudável: mais saudável e mais pura." (WOLFE, 2013, p. 21 - tradução do autor).

Posta, em breve parêntesis, uma parcela a pagar pelo ser humano à sacrificalidade que atinge animais não-humanos, urge agora se deter na possibilidade de redenção da animalidade não-humana, inclusive pelo próprio higienismo, quando ele se indispõe frente ao sangue derramado na cidade.

\section{Cidade sem sangue: redenção moral dos animais não-humanos?}

Frente ao higienismo que põe em xeque a animalidade por si, enquanto sujeira incurável (inclusive quando se volta contra seres humanos), vale dizer que o mesmo ensejou ainda o desejo de limpar as ruas do sangue (material e simbólico) que os atos violentos contra a animalidade derrubam ao chão.

Numa aporia a princípio paradoxal, a emergência do higienismo - que negativiza a animalidade - coincide com a estipulação de leis e regras de conduta que procuram banir a crueldade e a matança contra animais não-humanos na cidade. Assim, era comum encontrarmos a coexistência, no mesmo Código Municipal de Posturas (1900), o desejo de limpar as ruas da vida animal e o desejo de limpá-las dos atos que ameaçam derramar sangue desses corpos não-humanos, num continuum do mesmo processo.

\footnotetext{
${ }^{12} \mathrm{We}$ are returned, then, not just to the thanatopolitical site of the camps that takes center stage in Agamben's work, and not just to the question of the biopolitical status of Nazism, but also to the central function of race - and by extension, species - in modern biopolitics. As is well known, Foucault explores this topic in the lectures from 1975-6 collected in "Society Must Be Defended.". Racism, as Foucault notes, creates "caesuras within the biological continuum addressed by biopower"; it is "a way of fragmenting the field of the biological that power controls" so that some populations may be killed or allowed to die - what Foucault bluntly calls "indirect murder.". "In a normalizing society," he writes, "race or racism is the precondition that makes killing acceptable". And it has a second function, he argues: "the death of the bad race, of the inferior race (or the degenerate, the abnormal) is something that will make life in general healthier: healthier and purer.
} 
Emblemático é o caso do Matadouro Público diamantinense, construído no fim do século XIX, fruto de um higienismo que postula que a matança não deve mais ocorrer nos quintais e nas ruas da cidade. Desde então, ela deve ser confinada num espaço opaco, sob risco de poluir a cidade não só com o sangue físico desses animais, mas com a banalização dessa violência. A violência banalizada surge nesse horizonte como presença "animalesca", a ser removida de uma cidade higienizada, uma cidade civilizada.

Um dos desdobramentos avançados nesse saneamento do sangue animal da cidade, promovendo-se a invisibilidade do sofrimento que lhe é característico, está presente nas leis e regras de conduta (a princípio) erigidas em benefício das diversas espécies animais sofrentes - onde quer que esse contato ainda fosse entendido como inevitável.

Os atos - considerados "animalescos" - de crueldade devem ser banidos em uma sociedade civilizada e higienizada ${ }^{13}$. Assim, correlato à percepção ensejada por Elias (1993) de que nosso processo civilizatório quer limpar a sociedade da intrusão violenta do sangue, por ser considerado algo desumano, Juliana Vergueiro Dias entende que o abate humanitário na modernidade - que encontra seu auge na industrialização da matança - é uma forma mesmo de prolongar a eficiência dessa invisibilização, iniciada já pela construção dos matadouros municipais:

De modo mais importante, a autora [N. Vialles] demonstra que a transformação do animal em comestível é feita através de uma elipse lógica, que mascara a passagem do animal vivo ao corpo morto: a impessoalidade do abate industrial de animais, massivo e anônimo, apaga as imagens de violência e dor, criando um ambiente asséptico, mecânico e, idealmente, invisível. (DIAS, 2009, p. 83).

Ela conclui esse parágrafo, como corolário: "Isto se aplica, com maior propriedade, ao caso da insensibilização no abate humanitário, que aqui examino." (DIAS, 2009, p. 83).

Embora a figura do abate humanitário não seja em nenhum momento levada em conta pelos jornais que analisei - talvez por conta da fase pré-industrial da matança em Diamantina - existe já presente a caracterização dos animais não-humanos, em outras

\footnotetext{
${ }^{13}$ A caracterização da matança como algo "animalesco" é muito comum nos jornais. Em especial na ocasião de homicídios cometidos na cidade, seus autores e autoras são chamados de "feras", "lobos", etc. Como exemplo, consultar O Município, de 29 de março de 1901.
} 
ocasiões que não a da produção 'carnista' ${ }^{14}$, como seres passíveis de não serem tratados cruelmente.

O jornal O Município, por meio do Código de Posturas publicado em 1900, produz um horizonte de expectativas em sua população leitora no qual o processo de urbanidade perpassaria pela obrigatoriedade de um trato não-cruel com outras espécies animais. $\mathrm{O}$ artigo 91 proíbe a população diamantinense de "espancar animaes mansos, cortar a crina, a cauda ou maltratal-os: multa de 15\$000." (BIBLIOTECA ANTÔNIO TORRES. IPHAN-DIAMANTINA, 1900, p. 1). ${ }^{15}$

Esses desenvolvimentos estavam presentes em São Paulo, uma das mais progressistas capitais brasileiras dessa essa época. São Paulo fornecia um tópico nacional do que poderia/deveria ser o direcionamento do desenvolvimento diamantinense, e demais cidades do interior. Embora Aprobato Filho não tenha se atentado ao sentido comum subjacente à aparente contradição entre a perseguição de animais não-humanos e a estipulação de gentilezas devidas a eles - ele observa a presença das preocupações com o bem-estar animal em São Paulo: "Os animais, no contexto do planejamento urbano da cidade, através principalmente da legislação municipal, transformaram-se alvo constante de 'perseguição'. Em raros momentos, porém, foram vistos como formas de vida passíveis de proteção e cuidados." (APROBATO FILHO, 2006, p. 117).

Um indício de que o processo civilizatório prevê leis contra abusos a animais

\footnotetext{
${ }^{14}$ Uso o termo entre aspas simples para atentar uma rasura que sobreponho a esse conceito. Um primeiro problema do conceito 'carnista' é bem conhecido dos movimentos vegano-abolicionistas contemporâneos: ele parece negligenciar o fato de que ovos, leite e couro (e talvez o próprio mel, caso se confirme as abelhas como seres sencientes) são tecidos do corpo animal cujos processos extrativos objetificam o animal, imputando injustificadamente variáveis níveis de sofrimento contra eles. Um segundo problema, menos reconhecido, é que o termo - no afã de problematizar o consumo alimentício de tecidos corpóreos tirados de animais não-humanos (que o termo carnívoro tem por finalidade acriticamente ratificar) - acaba por reativar a legitimidade do termo carne, para designar o nome desses tecidos arrancados do corpo animal. Ao revalidar assim o termo carne, revalida-se a contrapelo a ideia de volúpia como inseparada do processo de mutilação animal - já que o termo carne também designa aqueles sentidos benevolentes à animalidade senciente (vide: "prazeres da carne"; "carnaval"). Esse uso inadvertido funciona como se o sujeito vegano-abolicionista fosse alguém que critica os poderes da volúpia - como se fosse, enfim, um asceta ao renegar a(os prazeres da) carne. Bem ao contrário, portanto, das bases éticas animalistas que se baseiam justamente na condição animal única de emular o seu prazer em detrimento de seu próprio sofrimento. Enfim, esse uso inadvertido atenta contra o próprio primado (hedonista) da senciência, que legitima a crítica à reiteração da mutilação de animais não-humanos. Por conta dessas impropriedades parciais do termo, decidi utilizá-lo entre aspas simples, como sinal de um uso sob rasura. Um termo melhor para esse paradigma, pois sem a ambiguidade referida, no que tange estritamente ao consumo alimentício de tecidos de animais não-humanos, seria algo como mutilívoro alguém que ingere mutilações.

${ }^{15}$ BIBLIOTECA ANTÔNIO TORRES. IPHAN-DIAMANTINA, MG. Código de posturas. O Município, Diamantina, 14 jul. 1900. p. 1.
} 
não-humanos - índice do grau de assepsia (moral) alcançado - encontra-se sintomaticamente em meio a um debate sobre a escravidão negra, pré-1888. Trata-se de uma crônica tecida por Ciro Arno, um dos articulistas do A Idéa Nova. Esse autor interpondo-se de início como questionador hesitante da real qualidade da urbanidade paulistana - diz que São Paulo fora um dos estados mais escravocratas. E que detinha, no século XIX, de má fama pelo tratamento cruel dispensado às pessoas negras escravizadas. Frente a tais argumentos, seu colega paulistano prontamente se defende, dizendo que as coisas haviam evoluído, e muito! E que o índice que atestava esse progresso era a existência, na capital paulistana, de uma "sociedade protetora de animais". O paulistano se defende com estas palavras:

- Nem todos os lavradores [senhores de escravo] eram crueis e deshumanos; muitos, porem, eram verdadeiros senhores feudaes, de baraço e cutello, terriveis, inexoraveis, gananciosos; as leis defensoras dos escravos eram desprezadas: destribuiam as torturas e os castigos physicos com uma ferocidade selvagem. Hoje os burros das carroças soffrem menos, porque já temos [até] uma Sociedade Protetora dos Animaes. (BIBLIOTECA ANTÔNIO TORRES. IPHAN-DIAMANTINA, 1909, p. 2). ${ }^{16}$

Segundo o historiador Peter Beatson (2009), na modernidade ocidental, o primeiro ato jurídico para evitar abusos e excessos contra animais teria ocorrido na Inglaterra, no ano de 1822. Esse ato, seguido de um gotejar de outras leis derivadas, culminaria na consecução do Ato de Proteção Animal, em 1911:

O caminho legislativo em direção à proteção animal começou com (inicialmente sem sucesso) tentativas parlamentares de colocar esportes sangrentos tais como açulamento de ursos, de touros, luta e rinha de cães e galos na ilegalidade, no Reino Unido. O primeiro sucesso legal real, e, portanto, um grande farol na história mundial das relações humanos/animais, foi um Ato promovido por Richard Martin em 1822 que tornou punível por multas e aprisionamento bater cruelmente, abusar, ou maltratar qualquer cavalo, égua, mula, besta, vaca, bezerro, ovelhas ou outro gado. Um escasso, mas significante gotejar de assuntos legislativos posteriores se seguiram ao rumo indicado pelo Ato de Martin. [...] Então, em 1911, 90 anos de legislação protecionista culminaram no Ato de Proteção dos Animais, que permaneceu como a pedra angular das leis britânicas de bem-estar animal por muitas décadas. ${ }^{17}$ (BEATSON, 2009, p. 53 - tradução do autor).

16 BIBLIOTECA ANTÔNIO TORRES. IPHAN-DIAMANTINA, MG. Urbe et orbe. A Idéa Nova, Diamantina. 31 jan. 1909. p. 2.

17 The legislative road to animal protection began with (initially unsuccessful) parliamentary attempts to have blood sports like bear-baiting, bull-baiting, dogfighting and cock-fighting outlawed in Britain. The first actual legislative success, and therefore a major milestone in the world history of human/animal relations, was an Act promoted by Richard Martin in 1822 that made it an offence punishable by fines and imprisonment to wantonly and cruelly beat, abuse, or ill-treat any horse, mare, gelding, mule, ass, cow, heifer, steer, sheep or other cattle. A meagre but significant trickle of further legislative measures followed the lead set by Martin's Act. [...] Then in 1911, 90 years of protective legislation culminated in the Protection of Animals Act, which was to remain the cornerstone of British animal welfare law for many decades to come. 
O desconhecimento específico e o direto de diamantinenses e paulistas a esses desenvolvimentos legais europeus não evade meu argumento de que havia um alcance globalizante subjacente a esse tipo de atitude. Mesmo porque a própria criação jurídica é resultado localizado de mudanças muito mais abrangentes que, emuladas pelo processo aqui em análise, passavam a compreender o derramamento de sangue como algo bastante "animalesco", e, portanto, sujo. Tal se dá na mesma medida em que era retratada como "animalesca" a modalidade de domínio corpo-a-corpo - a intrusão corporal - ensejada pela escravidão humana no texto de Ciro Arno.

Beatson, é claro, ao dizer que, ligado à ascensão das classes burguesas, as leis, buscando remover excessos, crueldades e abusos contra animais não-humanos - ou seja, leis bem-estaristas - tiveram sua origem no polimento moral moderno chamado

\title{
humanitarismo:
}

\begin{abstract}
A nova e mais terna moralidade que começou a se infiltrar na sensibilidade inglesa por volta de 250 anos atrás alterou a ênfase da estrita observância dos códigos de costume e das injunções religiosas em favor de qualidades que eu chamaria de "humanitarismo". Estou usando este termo num sentido abrangente, de modo a cobrir uma completa gama de emoções tais como pena, simpatia, gentileza, altruísmo, compaixão, benevolência, filantropia e humanidade. ${ }^{18}$ (BEATSON, 2009, p. 43 - tradução do autor).
\end{abstract}

Também situando a Inglaterra como o berço dessas novas atitudes, Keith Thomas (2001, p. 189) menciona o viés sociogênico dessas normas contra crueldades e abusos sanguinolentos. A "bestialidade" da crueldade e o caráter "animalesco" das cenas de sangue não cabia à economia psíquica daquelas classes que ansiavam pela higienização urbana.

Os jornais diamantinenses manifestam a presença desses desenvolvimentos. Tais jornais já incentivavam alguma gentileza com os cães (BIBLIOTECA ANTÔNIO TORRES. IPHAN-DIAMANTINA, 1907, p. 2). ${ }^{19}$ Esse tipo de situação está expresso em relação aos burros escravizados pelo tropeirismo, em pequenas crônicas jornalísticas: estes animais deveriam ser tratados com gentileza e gratidão

\footnotetext{
${ }^{18}$ The new, more tender-minded morality that began to infiltrate the English sensibility around 250 years ago shifted the emphasis away from the strict observance of customary codes and religious injunctions in favour of qualities I will call 'humanitarianism'. I am using this as an umbrella term to cover a whole range of selfless emotions like pity, sympathy, kindness, altruism, fellow-feeling, benevolence, philanthropy and humaneness.

19 BibliotecA ANTÔNIO TORRES. IPHAN-DiAmANTINA, MG. O mimoso. A Idéa Nova, Diamantina. 24 mar. 1907. p. 2.
} 
(BIBLIOTECA ANTÔNIO TORRES. IPHAN-DIAMANTINA, 1911, s/p). ${ }^{20}$

No trecho a seguir, Marcos Lobato Martins (2010) cita a existência de um dever - uma obrigação, não sendo possível saber se de ordem puramente moral ou já legal dos tropeiros de proporcionarem algum bem-estar aos animais que lhes estavam subordinados:

\begin{abstract}
O Mercado Municipal era o ponto de maior movimento da cidade, das cinco horas da manhã até por volta das seis horas da tarde. Durante todo o dia, o largo do Mercado e as ruas próximas ficavam cheios de animais, os quais deviam ser amarrados nos esteios, carregados ou descarregados cuidadosamente, ter os pêlos raspados - alguns levavam um banho de água com sal no lombo, para curar ferimentos provocados pela fricção da cangalha. (MARTINS, 2010, p. 168 - grifos meus).
\end{abstract}

Em outro texto desse autor, a presença de uma comiseração com esses animais pode também estar sub-repticiamente expressa. O depoimento do tropeiro Augusto Domingos Ribeiro a respeito da existência de fiscalização nos mercados municipais do Serro e de Diamantina aponta: "Neles, havia balança que o fiscal usava para pesar as mercadorias. O fiscal conferia as entregas e até olhava para as tropas. Se a tropa chegasse com um animal 'pisado' [maltratado] ou doente, o fiscal falava não! Esse animal não podia trabalhar mais, porque o fiscal não deixava.” (MARTINS, 2006, p. 1).

Certamente, uma maior parte das preocupações com esse bem-estar era nada mais que expressões do cuidado do senhorio com sua propriedade, sob o imperativo de evitar prejuízos materiais: item de uma (proto)racionalidade econômica. E o que é mais fatal é que esse tipo de preocupação assinava mais uma vez o pressuposto da legitimidade da propriedade sobre animais sofrentes, dotados de vontade própria, deixando-os à mercê dos humores variáveis de seu senhorio.

Exemplo arquetípico desse cuidado com os animais não-humanos na condição de propriedade encontra-se nos anúncios de pasto de aluguel, em que o locatário promete bom tratamento aos animais "de tropa". Isso evitaria prejuízos materiais por parte de quem alugava esse tipo de serviço: "LEVY LEITE DE FARIA. Acaba de abrir em sua chacara, sita à rua do Amparo d’esta cidade, excellentes pastos caprichosamente plantados e divididos, com magnifica agua. Estabeleceu tambem bem montada e cocheira onde os animaes serão tratados cuidadosamente." (BIBLIOTECA

20 BIBLIOTECA ANTÔNIO TORRES. IPHAN-DIAMANTINA, MG. Notícias. A Ideá Nova, Diamantina. 22 nov. 1911. s/p. 
ANTÔNIO TORRES. IPHAN-DIAMANTINA, 1909, p. 4 - grifo meu). ${ }^{21}$

Os jornais diamantinenses autenticavam a ideia de que animais não-humanos são propriedades - e que, subsequentemente, o cuidado com eles é um dos itens de uma (proto) racionalidade econômica. Nesse interim, a "raça suína" aparece como passível de ser perseguida, não pelo paradigma 'carnista' que os violentava sistematicamente, mas sim por uma doença que traz prejuízos ao seu senhorio:

\begin{abstract}
A raça suina é muito perseguida e victimada por uma peste denominada batedeira, e raro é o suino atacado que não morra desta molestia. Pois basta dar-lhes a folha da bananeira, que elles devorarão, para ficarem completamente bons e a molestia desapparecerá promptamente. (BIBLIOTECA ANTÔNIO TORRES. IPHAN-DIAMANTINA, 1899, p. 2). ${ }^{22}$
\end{abstract}

A mesma via - a da servidão enquanto propriedades - que prometia proteção e cuidado aos animais não-humanos trazia-lhes toda desgraça. O texto a seguir é bastante claro a esse respeito: "QUANTO DEVEM RENDER AS GALINHAS. Uma gallinha deve produzir annualmente mais do que cem ovos. Se produzir menos será preciso sacrifical-a: vendel-a ou comel-a para [o proprietário] não soffrer prejuizo." (BIBLIOTECA ANTÔNIO TORRES. IPHAN-DIAMANTINA, 1911, p. 2 ). ${ }^{23}$

Mesmo onde pôde haver preocupação sincera e afetuosa perante esses animais sofrentes (em possível contraposição com aquelas preocupações econômicoinstrumentais), a aceitação de que animais podem (devem) ser propriedades tornava essa boa intenção viciada. O teórico vegano-abolicionista Gary Francione (2013) nos esclarece o que reside no cerne do "fracasso" dessa abordagem bem-estarista:

O princípio do tratamento humanitário e as leis de bem-estar animal que supostamente incorporam como padrão legal professam reconhecer a posição de Bentham de que, como os animais são como nós (pois são sencientes), temos uma obrigação moral e legal direta para com eles de não lhe infligir sofrimento desnecessário. [...] O princípio do tratamento humanitário estabelece um padrão de equilíbrio; temos de equilibrar nossos interesses com os interesses dos animais para determinar se um uso ou tratamento animal em particular é necessário. (FRANCIONE, 2013, p. 122).

Porém tal abordagem comum baseia-se num vício estrutural, constituindo um falso dilema equivalente ao prefigurado pelos escravistas de seres humanos que - no

21 BIBLIOTECA ANTÔNIO TORRES. IPHAN-DIAMANTINA, MG. Anúncio. A Idéa Nova, Diamantina. 30 maio 1909. p. 4.

22 BIBLIOTECA ANTÔNIO TORRES. IPHAN-DIAMANTINA, MG. Notícias. O Município, Diamantina. 16 maio 1899. p. 2.

${ }^{23}$ BIBLIOTECA ANTÔNIO TORRES. IPHAN-DIAMANTINA, MG. Quanto devem render as galinhas.

A Idéa Nova, Diamantina. 12 nov. 1911. p. 2. 
século XIX - defendiam a escravização de negras e negros, sob argumento de os protegerem:

\begin{abstract}
Em tais situações, o que realmente equilibramos não são os interesses dos animais com os dos humanos de um modo abstrato, mas o interesse do proprietário em usar e tratar do animal de um modo específico com o interesse da propriedade, que, neste caso é o animal. É um absurdo, entretanto, falar em equilibrar os interesses da propriedade com os interesses dos donos da propriedade, já que a propriedade "não pode ter direitos ou deveres, nem reconhecer regras e obedecê-las". Como os animais são propriedades, tratamos todas as questões envolvendo seu uso ou tratamento como análogas à situação da casa em chamas, em que devemos escolher entre os interesses do humano e os do animal. O resultado é que escolhemos o interesse humano em vez do interesse do animal mesmo em situações em que o interesse do humano é trivial e o interesse do animal é fundamental, uma questão, literalmente, de vida ou morte. A escolha que realmente estamos fazendo, entretanto, é entre o interesse do dono da propriedade e o interesse de um item da propriedade. O resultado desse "conflito de interesses" está predeterminado. (FRANCIONE, 2013, p. 122).
\end{abstract}

O que importa aqui é salientar o cerne no qual reside a "ineficiência" 24 - do ponto de vista dos interesses animais não-humanos - dessas medidas humanitárias que visavam limpar a mancha vermelha do abuso e da crueldade contra esses animais: a ratificação reiterada nessas mesmas normativas do estatuto de propriedade instrumentos e/ou objetos - imputado a esses animais. "Ineficiência" patente mesmo quando essas normas por ventura declarassem abertamente como seus alvos beneficiários o bem-estar das propriedades, e não dos indivíduos feitos proprietários.

\title{
Limpar a cidade da vida \& limpar a cidade da morte
}

De fato, o que se apresenta nessas morais bem-estaristas é a radicalização de um dos termos (a saber, "humanidade", em detrimento de "animalidade") - termos pertinentes à dualidade fundamental construída pela civilização historicamente vivenciada (AGAMBEN, 2013; WOLFE, 2013). Assim, as leis anticrueldade frente a animais não-humanos são capítulo do desenvolvimento de uma civilização higienizada, na qual é a própria animalidade (o "animalesco") que deve ser superada como sujeira

\footnotetext{
${ }^{24}$ Se uso a palavra ineficiência entre aspas é porque entendo que as diretrizes contra os excessos foram bastante eficientes. A reafirmação reiterada do estatuto de propriedade sobre corpos não-humanos presentes nessas diretrizes bem-estaristas perfaz historicamente uma ampliação a nível global desse domínio, assujeitando-se quantitativamente cada vez mais corpos não-humanos como comida ou evidência científica (ADAMS, 2012), assujeitando-se qualitativamente essas vidas sofrentes a um controle totalitário e intensivo de cada uma de suas pulsões corporais a objetivos demasiadamente humanos. É o que, entre outras coisas, caracteriza a pecuária intensiva, os laboratórios vivissectores e as factory-farms desde o fim do século XIX (DERRIDA, 2002; DIAS, 2009).
} 
constituinte. A crueldade, a violência e a matança de seres sofrentes são apresentadas sob alguma desconfiança no mesmo gesto em que elas passam a ser entrevistas como índices de uma animalidade impura na urbe. Esses atos de sangue são considerados "bárbaros", "selvagens" e, fundamentalmente, "animalescos". Pois ao contrário do que se poderia (deveria) imaginar, essas primeiras normas bem-estaristas nasceram da emulação do mais refinado humanitarismo, e não de um possível animalitarismo. Portanto, de um polo (humano) da dualidade que historicamente se produziu a partir da renegação do seu oposto.

É justamente essa modulação antianimalidade ${ }^{25}$ - na qual o higienismo se produz - que se apresenta como o denominador comum aos termos contraditórios que podem ser claramente exemplificados na defesa da matança de cães que se conjuga, no mesmo jornal, à ideia que cães não deveriam ser violentados (a não ser por uma atitude "animalesca").

Talvez essa antítese que floresce em uma unidade de sentido comum esteja relacionada a uma "esquizofrenia" do processo civilizatório historicamente vivenciado. Tal processo, no afã de banir hábitos de intrusão corporal violenta, que levam o corpo à dor e ao sofrimento, baniu no mesmo gesto o intercurso corporal libidinal, que leva o corpo ao prazer e ao contentamento. A ambiguidade presente no banimento concomitante dos aspectos opostos de dor e prazer, de morte e de vida, é derivada dessa condenação absoluta das vicissitudes corporais ${ }^{26}$, intransitiva e não-qualificada. Esta, por sua vez, corresponde homologamente à postulação (também intransitiva) da animalidade como a sujeira, o pecado original, que deve ser superada por uma ascese civilizatória-higienista.

Mas, como se pode pressentir, a ambiguidade não se estanca na mera ambiguidade, sobredeterminada que é por essa modulação antinanimalidade. Relativamente a uma cara assimetria ontológica entre pulsões de vida e pulsões de morte na dinâmica psíquica, a denegação intransitiva de quaisquer pulsões instintivas pela civilização gera, no fim, a impotência de Eros em superar Tanatos, ainda que nunca totalmente. $\mathrm{Na}$ necessidade compartilhada por toda animalidade senciente (humana e não-humana) de se esvair do sofrimento, a repressão intransitiva das pulsões

\footnotetext{
${ }^{25}$ Essa modulação, que é também modulação sacrificial, parece extrapolar as fronteiras zoológicas tradicionais, detendo potencial para compreensão das relações erigidas inclusive no âmbito dos grupos humanos (AGAMBEN, 2013; WOLFE, 2013), conforme pincelado neste artigo.

${ }^{26}$ Corpo que é o índice materializado da presença animal no ente humano.
} 
impossibilita o contentamento pelas vias de Eros. A necessidade do não-sofrimento é então conduzida pela abreviação da vida, precipitação da morte, para acabar com a dor. O empate - a limpeza isomórfica dos contatos libidinais e dos contatos violentos (evidências da "barbárie animal" na urbe higienizada) - corresponde,portanto à vitória de Tanatos. Assim, a anulação das pulsões do corpo acelera a queda da vida na morte. Segundo Marcuse (1999),

\begin{abstract}
A tarefa cultural (a tarefa vital?) da libido - ou seja, tornar "inofensivo o instinto destrutivo" - fica reduzida a zero: o impulso instintivo em busca de satisfação total e fundamental regride do princípio do próprio prazer para o princípio do Nirvana [de morte]. A civilização reconheceu e sancionou esse perigo supremo: admira a convergência do instinto de morte e Eros nas superlativamente sublimadas e (monogâmicas) criações da Liebestod, enquanto proscreve as menos completas, porém mais realistas expressões de Eros como um fim em si. (MARCUSE, 1999, p. 62).
\end{abstract}

Finalmente, a reafirmação reiterada dos animais não-humanos como propriedades (coisas), presente transversalmente inclusive nos ordenamentos bemestaristas, é a própria expressão jurídica paroxística da valoração antianimalidade que subjaz a esses ordenamentos. É a própria ontologia (jurídica-histórica) da impossibilidade de libertação desses indivíduos não-humanos dos sofrimentos que lhes eram/são impostos. A ampliação qualitativa (capilar) e quantitativa do domínio mutilador sobre o corpo animal não-humano ${ }^{27}$ - tomado axiomaticamente como propriedade - é uma das faces mais esclarecedoras do triunfo de Tanatos sobre Eros na civilização asséptica que estive a analisar, na civilização historicamente vivenciada. De fato, os bilhões de animais não-humanos anuais submetidos às farm-factories e aos laboratórios vivissectores surgem como expressões arquetípicas, mas não únicas, dessa tragédia demasiadamente humana, a partir de um processo histórico em que, mais do que nunca, as cenas de sangue passaram a ser tão repudiadas...

\footnotetext{
${ }^{27} \mathrm{O}$ aumento exponencial do consumo de tecidos corpóreos de animais não-humanos, em termos absolutos e em termos per capita, é uma das características globais mais marcantes da alimentação humana desde o fim do século XIX. (ADAMS, 2012; DIAS, 2009). A libertação de animais não-humanos nessa modernidade surge como mero resíduo real. A respeito desse caráter residual, sugiro a leitura da conclusão de minha dissertação A imprensa e a proscrição dos animais não-humanos da urbe diamantinense (1894-1912).
} 


\section{REFERÊNCIAS}

\section{Fontes primárias}

BIBLIOTECA ANTÔNIO TORRES. IPHAN-DIAMANTINA, MG. Queixas. A Idéa Nova, Diamantina, 6 maio 1906. p. 3.

BIBLIOTECA ANTÔNIO TORRES. IPHAN-DIAMANTINA, MG. Club mata cães. A Idéa Nova, Diamantina. 29 jul. 1906. p. 1.

BIBLIOTECA ANTÔNIO TORRES. IPHAN-DIAMANTINA, MG. O mimoso. A Idéa Nova, Diamantina. 24 mar. 1907. p. 2.

BIBLIOTECA ANTÔNIO TORRES. IPHAN-DIAMANTINA, MG. Urbe et orbe. A Idéa Nova, Diamantina. 31 jan. 1909. p. 2.

BIBLIOTECA ANTÔNIO TORRES. IPHAN-DiAMANTINA, MG. Anúncio. A Idéa Nova, Diamantina. 30 maio 1909. p. 4.

BIBLIOTECA ANTÔNIO TORRES. IPHAN-DIAMANTINA, MG. Quanto devem render as galinhas. A Idéa Nova, Diamantina. 12 nov. 1911. p. 2.

BIBLIOTECA ANTÔNIO TORRES. IPHAN-DIAMANTINA, MG. Notícias. A Ideá Nova, Diamantina. 22 nov. 1911. s/p.

BIBLIOTECA ANTÔNIO TORRES. IPHAN-DIAMANTINA, MG. Devorado por cães. A Idéa Nova, Diamantina. 21 jan. 1912. p. 3.

BIBLIOTECA ANTÔNIO TORRES. IPHAN-DIAMANTINA, MG. Carta do Rio. O Jequitinhonha, Diamantina. 22 maio 1904. s/p.

BIBLIOTECA ANTÔNIO TORRES. IPHAN-DIAMANTINA, MG. Lagoa de Peçanha. O Jequitinhonha, Diamantina. 14 jul. 1904. s/p.

BIBLIOTECA ANTÔNIO TORRES. IPHAN-DIAMANTINA, MG. Notícias. O Município, Diamantina. 16 maio 1899. p. 2.

BIBLIOTECA ANTÔNIO TORRES. IPHAN-DIAMANTINA, MG. Código de posturas. O Município, Diamantina, 14 jul. 1900. p. 1.

BIBLIOTECA ANTÔNIO TORRES. IPHAN-DIAMANTINA, MG. Secção franca. O Município, Diamantina, 29 mar. 1901. p. 4.

\section{Fontes secundárias}

ADAMS, Carol. A política sexual da carne: a relação entre o carnivorismo e a dominância masculina. São Paulo: Alaúde Editorial, 2012. 
APROBATO FILHO, Nelson. O couro e o aço. Sob a mira do moderno: a "aventura" dos animais pelos "jardins" da Paulicéia, final do século XIX/ início do XX. Tese (Doutorado em História) - Universidade de São Paulo, Programa de Pós-graduação em História, São Paulo, 2006.

AGAMBEN, Giorgio. O aberto: o homem e o animal. Rio de Janeiro: Civilização Brasileira, 2013.

BEATSON, Peter. The motorised ark: the impact of modernity on animals. 2009. Disponível em: <http://www.massey.ac.nz/massey/fms/Colleges/College\%20of\% 20Humanities\%20and\%20Social\%20Sciences/PEP/PDF_documents/Sociology/Beatson /Animals\%20in\%20History \%20The\%20Impact\%20of\%20Modernity\%20.pdf >. Acesso em: 28 nov. 2013.

BEKOFF, MARC. A vida emocional dos animais. São Paulo: Cultrix, 2010.

DERRIDA, Jacques. O animal que logo sou. São Paulo: Editora UNESP, 2002.

DIAS, Juliana Vergueiro. O rigor da morte: a construção simbólica do animal de açougue na produção industrial brasileira. 2009. Dissertação (Mestrado em Antropologia) - Universidade de Campinas, Programa de Pós-graduação em Antropologia, Campinas, 2009.

ELIAS, Norbert. O processo civilizador. Trad. Ruy Jungman. Rio de Janeiro: Jorge Zahar, 1993.

FRANCIONE, Gary. Introdução aos direitos animais. Campinas: Editora Unicamp, 2013.

GOODWIN Jr., James William. Cidades de papel: imprensa, progresso e tradição. Diamantina e Juiz de Fora (1884-1914). 2007. Tese (Doutorado em História) Universidade de São Paulo, Programa de Pós-graduação em História, São Paulo, 2007.

LESTEL, Dominique. As origens animais da cultura. São Paulo: Editora Piaget, 2002.

LIMA, Nísia Trindade. Um sertão chamado Brasil: intelectuais e representação geográfica da identidade nacional. Rio de Janeiro: Revan, IUPERJ-UCAM, 1999.

LOPES, Gustavo. A imprensa e a proscrição dos animais não-humanos da urbe diamantinense (1894-1912). Dissertação (Mestrado) - Universidade Federal dos Vales do Jequitinhonha e Mucuri, Programa de Pós-Graduação em Ciências Humanas. Diamantina, 2016.

MAGNANI, Maria. Hospício da Diamantina - a loucura na cidade moderna. 2004. Dissertação (Mestrado em História) - Fundação Oswaldo Cruz, Programa de Pósgraduação em História, Rio de Janeiro, 2004.

MARCUSE, Herbert. Eros \& civilização: uma interpretação filosófica do pensamento de Freud. Rio de Janeiro: LTC, 1999. 
MARTINS, Marcos Lobato. Quintais, chácaras, intendências e abastecimento alimentar em Diamantina: séculos XIX e XX. XIV. In: SEMINÁRIO SOBRE A ECONOMIA MINEIRA, 14, 2010, Diamantina. Disponível em: <http://web.cedeplar.ufmg.br/cedeplar/site/seminarios/seminario_diamantina/2010/D10 A003.pdf >. Acesso em: 28 nov. 2013.

SANTOS, Dayse. O padrão idealizado de família e de mulher em Diamantina e região 1860 a 1930. Unimontes Científica, Montes Claros, v. 5, n. 2, p. 67-84, jul./dez. 2003. Disponível em: <http://www.ruc.unimontes.br/index.php/unicientifica/article/view/ 160/152>. Acesso em: 27 nov. 2014.

SENNETT, Richard. Carne e pedra: o corpo e a cidade na civilização ocidental. Trad. Marcos Aarão Reis. Rio de Janeiro: Record, 2003.

THOMAS, Keith. O homem e o mundo natural: mudanças de atitude em relação às plantas e aos animais (1500-1800). São Paulo: Editora Schwarcz, 2001.

WOLFE, Cary. Before the law humans and other animals in a biopolitical frame. 2013. Disponível em: <http://fsi.stanford.edu/sites/default/files/evnts/media/wolfebefore_law_exc.pdf $>$. Acesso em: 20 out. 2014. 